\title{
Selective rehearsal and selective recall
}

\author{
MARGARET W. MATLIN \\ State University of New York, Geneseo, New York 14454 \\ and \\ WENDY A. UNDERHILL \\ University of Rhode Island, Kingston, Rhode Island 02881
}

\begin{abstract}
The purpose of this experiment was to determine whether pleasant words are rehearsed more frequently than less pleasant words and whether this "selective rehearsal" could account for "selective recall," the superior recall of pleasant words in contrast with less pleasant words. English words varying in pleasantness were learned using a free recall paradigm. One group of 24 subjects performed the task using the overt rehearsal technique; they were instructed to say out loud the words they would normally rehearse silently. Another group of 24 subjects used standard covert rehearsal. The results showed that (1) pleasantness was related to rehearsal frequency, (2) rehearsal frequency was related to recall, and (3) pleasantness was related to recall in only one of the four conditions.
\end{abstract}

"The canonization of saints, the apotheosis of strenuous historical characters, the obituaries of our friends, the reminiscences of childhood, all testify in this natural and universal habit of forgetting the bad and exalting the good." With these words, Hollingworth (1910, p. 710) began his summary of the limited research and extensive speculation of two decades on the topic of selective recall. Hollingworth's article set the stage for more than six decades of research on this topic. We have recently reviewed the literature on selective recall (Matlin \& Stang, 1978, Chapter 7), and we found that 60 of the 99 published studies demonstrated selective recall. In general, pleasant experiences are recalled more accurately than less pleasant experiences, and pleasant word lists are learned and recalled more accurately than less pleasant word lists. However, most of the studies have concerned themselves with demonstrating the phenomenon of selectivity; only a few have attempted to identify the mechanism of selectivity.

We (Matlin \& Stang, 1978) have proposed that "selective rehearsal" might be an important factor in the selective recall phenomenon. When subjects learn lists of words, they may rehearse the pleasant words in the list more frequently than the neutral or unpleasant words. Consequently, pleasant words might be more likely to be retained in memory. The concept of selective rehearsal has received only limited attention in two early studies (Menzies, 1935; Waters \& Leeper, 1936), in which rehearsal was assessed by asking subjects to estimate how often they had thought about items varying in pleasantness. Neither study showed evidence for the selective rehearsal that we have proposed. Clearly, more accurate

This research was supported by a grant from the State University of New York Research Foundation. An earlier version of the paper was presented at the annual convention of the Eastern Psychological Association, Washington, D.C., 1978. methods of assessing rehearsal frequency would be desirable.

The present study examines the relationship among pleasantness, rehearsal, and recall using the overt rehearsal procedure. This technique, as developed by Rundus (Rundus, 1974; Rundus \& Atkinson, 1970), requests subjects to rehearse out loud the words they would normally rehearse covertly. Examination of subjects' output provides an index of the frequency with which each word is rehearsed. This index of rehearsal frequency can be used to determine (1) whether pleasantness is related to rehearsal frequency, (2) whether rehearsal frequency is related to probability of recall, and (3) whether pleasantness is related to probability of recall after controlling for rehearsal frequency.

\section{METHOD}

One group of 24 subjects learned lists of words using the overt rehearsal procedure. Another group of 24 subjects learned the words in the traditional fashion and did not report their rehearsals. The second condition was included because it resembled the natural conditions under which subjects performed in the previous 99 selective recall experiments. However, their data could be examined for evidence of the operation of selective rehearsal by using an index of rehearsal obtained on each word from the overt rehearsal $(0)$ group.

\section{Subjects}

Subjects were 48 female college students enrolled in a course in introductory psychology. Each subject was tested individually by the second author. Subjects were assigned, in order of participation in the experiment, to a condition (overt rehearsal, $\mathrm{O}$, or covert rehearsal, C), a group (A or B), and a presentation order $(1,2,3$, or 4$)$.

\section{Material}

A group of 120 words was selected from the semantic atlas of Jenkins, Russell, and Suci (1958). Forty words were pleasant $(100-250), 40$ were neutral $(325-475)$, and 40 were unpleasant. (550-700). The three categories were equivalent with respect to part of speech and word length. 
Two groups of four lists each were constructed in the following manner. For Group A, 10 words from each category were randomly assigned to each of four lists. Each list therefore contained 30 words, of which 10 were pleasant, 10 were neutral, and 10 were unpleasant. For Group B, the process of random assignment was repeated, thus forming four new lists of 30 words each. Word order within each of the lists was randomized. For each group, the order of presentation for the four lists was counterbalanced across subjects.

\section{Procedure}

Subjects in the $C$ group participated in a standard free recall experiment. They were instructed to "study the words in the normal way you would ordinarily study them." The words were presented in a Lafayette memory drum at a rate of $4 \mathrm{sec} / \mathrm{item}$. After a list of 30 words had been presented, the subjects were allowed a 2 -min written free recall period. Four lists were presented, with the first list being designated as a practice list. (The practice list familiarized subjects with the procedure; data from this list were not included in the analysis.) A 1-min break was provided after each study-test trial. An unexpected written free recall test followed the presentation of all lists. On this test, subjects were allowed a 5-min period for recall of words from the three most recent lists.

Subjects in the $O$ group performed the same tasks in the same order. However, they were told, "I want you to study the words in the normal way you would ordinarily study them, except for one thing. That is, every time you think about an item on the list, I want you to say that item out loud." Like the $\mathrm{C}$ group, they had four lists, with the first list designated as a practice list. A casette tape recorder was used to record the subjects' overt rehearsal.

Subjects answered a postexperimental questionnaire at the end of the experiment. One purpose of the questionnaire was to determine whether subjects in the $O$ condition had covertly rehearsed any category of words that they did not report out loud.

\section{RESULTS}

In the analyses of the data, the 120 words served as subjects. For each word, the following data were recorded: (1) pleasantness, or "good-bad" rating on the Jenkins et al. (1958) norms, (2) number of times the word was rehearsed by the $O$ subjects, (3) number of times the word was recalled by the $\mathrm{O}$ subjects immediately after presentation, (4) number of times the word was recalled by the $\mathrm{C}$ subjects immediately after presentation, (5) number of times the word was recalled by $O$ subjects during delayed free recall, (6) number of times the word was recalled by $\mathrm{C}$ subjects during delayed free recall, (7) word frequency as listed in the KuxeraFrancis (1967) norms, and (8) rating on the "activity" scale of the Jenkins et al. (1958) norms. The last two measures were included in the analyses because inspection of the lists showed that the pleasant words were higher in frequency and activity than the other words. (The "potency" scale was not included because pleasant ness was not related to potency on these lists.)

\section{Pleasantness as a Determinant of Rehearsal Frequency}

We first determined whether pleasant words were rehearsed more frequently than less pleasant words. A stepwise multiple-regression analysis was performed on the data, using pleasantness, activity rating, and word frequency as independent variables and number of times the word was rehearsed by the $\mathrm{O}$ subjects as the dependent variable. The analysis showed that pleasantness was significantly related to the number of rehearsals, even when activity rating and word frequency were included in the multiple regression (beta $=-.18 ; \mathrm{F}=3.74$, $\mathrm{p}<.05$ ). More pleasant words were rehearsed more frequently than less pleasant words. Activity rating and word frequency were not significantly related to number of rehearsals.

\section{Pleasantness as a Determinant of Recall}

We performed a series of stepwise multiple-regression analyses on the data, using six different measures of recall as the dependent variables. In each case, pleasantness was forced to enter on Step 1, word frequency and activity rating were forced to enter on Step 2, and number of rehearsals by $\mathrm{O}$ subjects was forced to enter on Step 3. These analyses allowed us to answer several questions: (1) Is pleasantness initially a determinant of recall? (2) Is pleasantness a determinant of recall after controlling for the confounding factors of word frequency and activity rating? (3) Is pleasantness a determinant of recall after controlling for the confounding factors and numbers of rehearsals? (4) Are word frequency, activity rating, or number of rehearsals determinants of recall?

First, examine the data for recall measures obtained immediately after the subjects viewed the list. As Table 1 shows, pleasantness was not a significant determinant of recall. This is true when both $\mathrm{O}$ and $\mathrm{N}$ groups are combined, and in the individual analyses of the $\mathrm{O}$ and $\mathrm{N}$ groups. These results are consistent with the previous literature; Matlin and Stang (1978) found that only $45 \%$ of studies testing immediate recall demonstrated selectivity, in contrast with $75 \%$ of studies testing delayed recall.

Now, examine the data for recall measures obtained after a delay, at the end of the testing session. In the analysis of the $\mathrm{C}$ group, pleasantness was not significantly related to recall at any step in the multiple regression. For the $\mathrm{O}$ group, pleasantness was a significant determinant of recall initially, and it remained significant after correcting for word frequency and activity. However, after correcting for number of rehearsals, at Step 3, pleasantness was no longer a significant determinant of recall. Thus, pleasantness was not significantly related to recall for this group, once rehearsal frequency has been controlled.

\section{Other Factors as Determinants of Recall}

We now consider whether rehearsal frequency, word frequency, or activity was a determinant of recall in the multiple-regression analysis. As Table 1 shows, rehearsal frequency was a highly significant determinant of recall. This was true in both immediate and delayed recall and 
Table 1

Multiple Regression Analyses to Predict Recall

\begin{tabular}{|c|c|c|c|c|c|c|c|c|c|c|c|c|c|c|c|c|c|c|c|}
\hline \multirow[b]{4}{*}{ Variable } & \multirow[b]{4}{*}{ Step } & \multicolumn{18}{|c|}{ Condition } \\
\hline & & \multicolumn{9}{|c|}{ Immediate Recall } & \multicolumn{9}{|c|}{ Delayed Recall } \\
\hline & & \multicolumn{3}{|c|}{ Combined } & \multicolumn{3}{|c|}{ Overt } & \multicolumn{3}{|c|}{ Covert } & \multicolumn{3}{|c|}{ Combined } & \multicolumn{3}{|c|}{ Overt } & \multicolumn{3}{|c|}{ Covert } \\
\hline & & $\beta$ & $\mathrm{F}$ & $\mathbf{P}$ & $\beta$ & $\mathbf{F}$ & $\mathbf{P}$ & $\beta$ & $\mathrm{F}$ & $\mathbf{P}$ & $\beta$ & $\mathbf{F}$ & $\mathbf{P}$ & $\beta$ & $\mathbf{F}$ & $\mathbf{P}$ & $\beta$ & $\mathbf{F}$ & $\mathbf{P}$ \\
\hline Evaluation & $\begin{array}{l}1 \\
2 \\
3\end{array}$ & $\begin{array}{l}-.10 \\
-.07 \\
-.02\end{array}$ & $\begin{array}{r}1.31 \\
.65 \\
.31\end{array}$ & $\begin{array}{l}.254 \\
.423 \\
.861\end{array}$ & $\begin{array}{l}-.17 \\
-.14 \\
-.09\end{array}$ & $\begin{array}{r}3.48 \\
2.27 \\
.99\end{array}$ & $\begin{array}{l}.065 \\
.135 \\
.320\end{array}$ & $\begin{array}{r}-.02 \\
.00 \\
.06\end{array}$ & $\begin{array}{l}.49 \\
.17 \\
.48\end{array}$ & $\begin{array}{l}.826 \\
.967 \\
.487\end{array}$ & $\begin{array}{l}-.21 \\
-.16 \\
-.09\end{array}$ & $\begin{array}{l}5.31 \\
3.20 \\
1.23\end{array}$ & $\begin{array}{l}.023 \\
.076 \\
.270\end{array}$ & $\begin{array}{l}-.24 \\
-.18 \\
-.11\end{array}$ & $\begin{array}{l}6.94 \\
4.06 \\
1.82\end{array}$ & $\begin{array}{l}.010 \\
.046 \\
.180\end{array}$ & $\begin{array}{l}-.15 \\
-.12 \\
-.06\end{array}$ & $\begin{array}{r}2.74 \\
1.77 \\
.51\end{array}$ & $\begin{array}{l}.100 \\
.187 \\
.478\end{array}$ \\
\hline Activity & 3 & .07 & .59 & .443 & .02 & .53 & .819 & .10 & 1.37 & .243 & .02 & .12 & .733 & .01 & .13 & .910 & .04 & .25 & .616 \\
\hline Frequency & 3 & .15 & 3.01 & .086 & .15 & 2.75 & .100 & .13 & 2.17 & .144 & .23 & 7.51 & .007 & .29 & 12.83 & .000 & .13 & .234 & .129 \\
\hline Rehearsals & 3 & .33 & 13.62 & .000 & .27 & 9.05 & .003 & .33 & 13.40 & .000 & .37 & 19.43 & .000 & .36 & 19.36 & .000 & .33 & 13.93 & .000 \\
\hline
\end{tabular}

Note-Next to each variable is listed the step at which beta ( $\beta)$ is assessed; thus, assessments of beta for the evaluation variable are provided at all three steps.

for both $\mathrm{O}$ and $\mathrm{C}$ subjects. In other words, items that are frequently rehearsed are accurately recalled. A second factor, word frequency, was a significant factor only in predicting delayed recall for the $\mathrm{O}$ condition. The last factor, activity, proved to be nonsignificant in all analyses.

\section{Results of the Postexperimental Questionnaire}

An examination of the postexperimental questionnaire showed that most subjects thought we were testing hypotheses concerning interference or word associations, or some other hypotheses unrelated to word pleasantness. None of the subjects guessed that we expected pleasantness to be related to either rehearsal frequency or probability of recall. The last item on the questionnaire, which only the subjects in the $O$ group answered, was, "Are there any kind of words you may have thought about but not said aloud?" We were particularly concerned that subjects might have been covertly rehearsing some of the unpleasant words but not reporting them overtly. Four of the 24 subjects replied, "Yes," but 2 of the subjects qualifed their answers to specify some dimension other than pleasantness; it is possible that the remaining 2 subjects with the unqualified "yes" responses may have suppressed overt rehearsal of unpleasant words. It does not seem, then, that report suppression accounted for a large proportion of the effect of pleasantness on rehearsal frequency. Undoubtedly report suppression would be a significant concern with ego-threatening or taboo stimuli, but it is not critical in this experiment, in which the words were merely unpleasant (e.g., discomfort, anger, mosquito).

\section{DISCUSSION}

The mechanisms and effects of rehearsal have been attracting increased attention from psychologists interested in memory, particularly in conjunction with Craik and Lockhart's (1972) levels-of-processing hypothesis. A portion of these studies have tried to explain various free recall phenomena in terms of rehearsal patterns. Rundus and Atkinson (1970) presented evidence that the primacy effect in the serial position curve was due to increased rehearsal for the early items in the list. In a later paper, Rundus (1971) demonstrated that extra reheasal for certain items on a list could explain the von Restorff effect and Melton's (1967) spacing effect. Rundus also showed that organizational patterns in rehearsal were related to clustering in free recall.

The present paper attempted to determine whether rehearsal patterns could also explain selective recall. Do people recall pleasant words better than less pleasant words because they rehearse pleasant words more frequently and because frequently rehearsed words are recalled more accurately?

The study demonstrated that pleasantness is, indeed, related to rehearsal frequency. Pleasant words are rehearsed more frequently than other words. Furthermore, rehearsal frequency is related to recall. In all analyses, involving both immediate and delayed recall and both overt and covert rehearsal, words that have been rehearsed frequently are recalled better. This observation is particularly relevant to the continuing debate about the relationship between rehearsal and delayed recall. Some studies have shown that rehearsal is not related to later retention (e.g., Craik \& Watkins, 1973; Jacoby, 1973). Other studies have indicated that rehearsal influences recognition memory but not recall (Glenberg, Smith, \& Green, 1977; Woodward, Bjork, \& Jongeward, 1973). Still others have demonstrated that rehearsal does indeed enhance delayed recall (e.g., Dark \& Loftus, 1976; Meunier, Kestner, Meunier, \& Ritz, 1974; Nelson, 1977; Rundus $\&$ Atkinson, 1970). The results of the present study add support to the last category of studies. Clearly, the relationship between rehearsal and recall must depend upon variables in the experimental procedure, but these variables remain to be identified.

Can the combination of two relationships-the relationship between pleasantness and frequency and the relationship between frequency and recall-explain selective recall? Unfortunately, in this study the two explanatory mechanisms were more potent than the selective recall phenomenon that they were hypothesized to explain. After controlling statistically for confounding variables, there was no significant relationship between pleasantness and recall for three of the four conditions. Thus, this study has demonstrated that selective rehearsal is an attractive explanation for the selective recall phenomenon, but the ephemeral nature of the selective recall phenomenon diminishes the impact of this finding.

\section{REFERENCES}

Craik, F. I. M., \& Lockhart, R. S. Levels of processing: A framework for memory research. Journal of Verbal Learning and Verbal Behavior, 1972, 11, 671-684.

Craik, F. I. M., \& Watkins, M. J. The role of rehearsal in 
short-term memory. Journal of Verbal Learning and Verbal Behavior, 1973, 12, 599-607.

DARK, V. J., \& Loftus, G. R. The role of rehearsal in long-term memory performance. Journal of Verbal Learning and Verbal Behavior, 1976, 15, 479-490.

Glenberg, A., Smith, S. M., \& Green, C. Type I rehearsal: Maintenance and more. Journal of Verbal Learning and Verbal Behavior, 1977, 16, 339-352.

Holling WORTH, H. The oblivescence of the disagreeable. Journal of Philosophy, Psychology, \& Scientific Methods, 1910, 7, 709-714.

JАСову, L. L. Encoding process, rehearsal, and recall requirements. Journal of Verbal Learning and Verbal Behavior, $1973,12,302-310$

Jenkins, J. J., Russell, W. A., \& Suci, G. J. An atlas of semantic profiles for 360 words. American Journal of Psychology, 1958, 71, 688-699.

Kučera, H., \& Francis, W. N. Computational analysis of present-day American English. Providence, R.I: Brown University Press, 1967.

Matlin, M. W., \& Stang, D. J. The Pollyanna principle: Selectivity in language, memory, and thought. Cambridge, Mass: Schenkman, 1978.

Melton, A. W. Repetition and retrieval from memory. Science, $1967,158,532$.
Menzies, R. The comparative memory values of pleasant, unpleasant, and indifferent experiences. Journal of Experimental Psychology, 1935, 18, 267-279.

Meunier, G. F., Kestner, J., Meunier, J. A., \& Ritz, D. Overt rehearsal and long-term retention. Journal of Experimental Psychology, 1974, 102, 913-914.

Nelson, T. O. Repetition and depth of processing. Journal of Verbal Learning and Verbal Behavior, 1977, 16, 151-171.

Rundus, D. An analysis of rehearsal processes in free recall. Journal of Experimental Psychology, 1971, 89, 63-77.

Rundus, D. Output order and rehearsal in multi-trial free recall. Journal of Verbal Learning and Verbal Behavior, 1974, 13, 656-663.

Rundus, D., \& Atrinson, R. C. Rehearsal processes in free recall: A procedure for direct observation. Journal of Verbal Learning and Verbal Behavior, 1970, 9, 99-105.

WATERS, R. H., \& LEEPER, A. The relation of affective tone to the retention of experiences of daily life. Journal of Experimental Psychology, 1936, 19, 203-215.

Woodward, A. E., Jr., BJork, R. A., \& Jongeward, R. H. Recall and recognition as a function of primary rehearsal. Journal of Verbal Learning and Verbal Behavior, 1973, 12, 608-617.

(Received for publication August 28, 1979.) 